\title{
BMJ Open Community factors associated with stunting, overweight and food insecurity: a community-based mixed- method study in four Andean indigenous communities in Ecuador
}

\author{
Jemie Walrod, ${ }^{1}$ Erica Seccareccia, ${ }^{1}$ Iván Sarmiento, ${ }^{1}$ Juan Pablo Pimentel, ${ }^{1}$ \\ Shivali Misra, ${ }^{1}$ Juana Morales, ${ }^{2}$ Alison Doucet, ${ }^{1}$ Neil Andersson ${ }^{1}$
}

To cite: Walrod J,

Seccareccia E, Sarmiento I, et al. Community factors associated with stunting, overweight and food insecurity: a community-based mixedmethod study in four Andean indigenous communities in Ecuador. BMJ Open 2018;8:e20760. doi:10.1136/ bmjopen-2017-020760

- Prepublication history and additional material for this paper are available online. To view these files, please visit the journal online (http://dx. doi org/10.1136/bmjopen-2017020760).

JW and ES contributed equally.

Received 21 November 2017 Revised 30 March 2018 Accepted 22 May 2018

Check for updates

${ }^{1}$ Department of Family Medicine, McGill University, Montreal, Canada

${ }^{2}$ Indigenous Community of Chilcapamba, Chilcapamba, Ecuador

Correspondence to Iván Sarmiento;

ivan.sarmiento@mail.mcgill.ca

\section{ABSTRACT}

Objectives We aimed to implement participatory research to answer a question posed by four Kichwa indigenous communities in Andean Ecuador about what actionable factors are associated with childhood stunting, overweight and food insecurity among their people.

Design We used mixed methods including household questionnaires, discussion groups with respondents of the questionnaires and anthropometric measurement of children (6 months to 12 years) from surveyed households. Setting The study involved four Andean indigenous communities transitioning from traditional to Western lifestyles. They subsist mainly on small-scale agriculture and have a rich cultural heritage including their traditional language.

Participants Anthropometric data were collected from 298 children from 139 households in four communities; all households completed the questionnaire. We held five discussion groups (6-10 participants each): three composed of mothers and two of farmers.

Primary and secondary outcome measures Primary outcomes were stunting, overweight, food insecurity and their relationship with demographics, dietary habits and agricultural habits.

Results 0 298 children, $48.6 \%$ were stunted and $43.3 \%$ overweight for age. Stunted children were more likely to live in households that sold livestock (ORa 1.77, 95\% Cla 1.06 to 2.95 ) and with illiterate primary caretakers (ORa $1.81,95 \%$ Cla 1.07 to 3.06 ), but were less likely to live in households with irrigation (ORa $0.47,95 \%$ Cla 0.27 to 0.81). Overweight children were more likely to be male (ORa 1.87, 95\% Cla 1.02 to 3.43 ) and live in a household that sold livestock (ORa 2.14, 95\% Cla 1.14 to 4.02). Some $67.8 \%$ of children lived in a household with food insecurity, more frequently in those earning below minimum wage (ORa 2.90, 95\% Cla 1.56 to 5.41) and less frequently in those that ate quinoa in the past 24 hours (ORa $0.17,95 \%$ Cla 0.06 to 0.48 ). Discussion groups identified irrigation and loss of agricultural and dietary traditions as important causes of poor childhood nutrition.

Conclusion Many indigenous communities face tumultuous cultural, nutritional and epidemiological transitions. Community-based interventions on factors identified here could mitigate negative health outcomes.

\section{Strengths and limitations of this study}

Participating communities initiated the research and defined the research question.

- We combined quantitative measurement (including anthropometry) with qualitative group discussions.

- Data collection in the local language relied on local community members fluent in Kichwa and Spanish.

- The small size of participating communities limited statistical power in quantitative analysis.

- 24 hours dietary histories provided only a limited snapshot of food habits.

\section{INTRODUCTION}

Ecuador is a geographically and ethnically diverse country, with 14 indigenous groups representing $7 \%$ of the total population (approximately 1 million individuals). ${ }^{1}$ The Andean Kichwa are one of the largest indigenous groups in the country. ${ }^{2}$ Among indigenous communities, some $42 \%$ children under 5 years of age are stunted compared with $18 \%-24 \%$ of their non-indigenous counterparts. ${ }^{2} 3$ However, this proportion varies between populations in the Andean mountains, the Pacific coast and the Amazon region. ${ }^{4}$ Direct causes of malnutrition (and resulting stunting) are inadequate caloric intake and high burden of disease, but there are complex social factors that predispose a child to stunting including maternal education, socioeconomic status and income. ${ }^{5}$ Factors related to poor nutritional status have been studied in the Amazonian indigenous populations of Ecuador, ${ }^{6}$ but the evidence is less clear for the Andean indigenous populations, ${ }^{7}$ where there are additional physiological and agricultural stresses related to living at high altitude. ${ }^{8}$ 
Multiple factors affect a child's risk of malnutrition, and there are many consequences to being malnourished. Malnutrition (defined as poor anthropomorphic measures) could underlie as much as $50 \%$ of early childhood mortality, and has been found to be associated specifically with increased mortality rate of diarrhoea and acute respiratory illness. ${ }^{9}$ Additional consequences of malnutrition include shorter adult height, less schooling (possibly related to duration of childhood illnesses) and reduced economic productivity. ${ }^{10}$ Because of their smaller stature, children who grow up with malnutrition are at a greater risk of being overweight (weight related to height) as adults ${ }^{11}$; this trend is visible throughout Latin America with increasing rates of overweight.

Recent evidence indicates that the prevalence of overweight is related to nutritional and epidemiological transitions associated with market integration, defined here as the degree of production for and consumption from a market-based economy, whereby communities have increased participation in and dependence on markets for food resources. ${ }^{12-14}$ This integration can change diet and physical activity, ${ }^{2}$ shifting from a diet of traditional grains and hunter-gatherer lifestyle to a diet of processed foods high in fats and sugars and sedentary lifestyle. ${ }^{14}{ }^{15}$ Frequently, an epidemiological transition follows the nutritional transition, with infectious and maternal/perinatal diseases being replaced by cardiovascular and metabolic diseases. ${ }^{16}$ There is some evidence for this trend in indigenous populations of Amazonian Ecuador, where changes in body size, cholesterol level and blood pressure have been documented in relation to degree of market integration. ${ }^{12} 17$ The healthcare system in Ecuador is not prepared to deal with this dual burden of stunting and obesity (and the diseases associated with each $)^{18}$ and its costs, both in terms of morbidity/mortality and financial. ${ }^{1219}$

The Training and Education for Andean Community Health (TEACH) programme is a partnership between the McGill University Department of Family Medicine and the participating indigenous communities that strives to improve health via training community health workers (CHW). In this context, this study is a collaboration with four communities that asked for assistance to research nutrition and agriculture, with a view towards community action to address their health concerns. Our objective was to implement a participatory approach to identify the factors associated with childhood stunting, overweight and food insecurity among four Kichwa Andean indigenous communities. ${ }^{20}$ We hypothesised that most of these factors were associated with cultural transition towards a Western lifestyle.

\section{METHODS}

We conducted the study during July and August of 2013 and 2014 in four communities (Chilcapamba, Morales Chupa, Iltaqui and Arrayanes) in Ecuador (Northern Andes), between 5 and $15 \mathrm{~km}$ from Cotacachi, where the nearest market and hospital are located. As indigenous subsistence farming communities, agriculture faces the challenges of rugged and mountainous terrain and seasonally dry climate (average yearly rainfall $906 \mathrm{~mm}){ }^{21}$ Typical crops grown by these communities include corn, peas, beans and potatoes. Typical livestock raised are chickens and guinea pigs which are used to feed the household. Some households also raise pigs or cows, mainly to be sold at a community market.

The mixed-method approach included three components: (1) discussion groups with farmers and mothers, (2) questionnaires administered to all households without sampling and (3) anthropometric measurement of children without sampling. We collaborated with the CHW as an intercultural team to adjust research instruments that capture the local context and promote engagement of participants in the project. The CHW decided the research topic (ie, childhood malnutrition, stunting and agriculture) with input from their four communities. Together with the CHW, the researchers identified three related outcomes: childhood overweight, stunting and food insecurity, as core indicators of nutritional state. We then specified factors potentially related to those outcomes including household demographics, productive activities, sales of crops and livestock, and food consumption habits. We included these items in the questionnaires.

\section{Discussion groups}

Discussion groups with farmers and mothers of the communities took place in July and August 2014. The goal of these discussion groups was to develop an understanding of the communities' perspective to guide interpretation of quantitative data. In addition, group discussion is key to engage communities in meaningful reflections to identify actionable factors to promote change. ${ }^{22}$ The CHW recruited community members for these groups. We aimed to run two groups in each community (except in Chilcapamba, as this community was surveyed in 2013): one with mothers and one with farmers, with about 10 participants each. Discussion was in Kichwa and Spanish based on the preference of the participants. A CHW moderated each group and posed the discussion question.

Discussion was initiated by asking a sole question in each group. The CHW asked mothers why they feel nutrition is a problem in their community and farmers why they think agriculture changed in their community in recent years. Discussion was concluded by having the CHW list the factors raised during discussion and asking the group to rate their importance on a scale of $1-5 ; 1$ being least important and 5 being most important.

Two authors (JW and ES) with the assistance of CHW took notes on the discussion of factors relating to nutrition and agriculture. We chose not to audio record these groups under advice from the CHW who felt it would impact the quality of the discussion. 


\section{Questionnaire}

The authors (SM in Chilcapamba, JW and ES in all other communities) accompanied by a CHW administered the questionnaire to each household with children between 6 months and 12 years of age. We offered the questionnaire to all qualifying households. This questionnaire included 62 items and is available as an online supplementary file.

The CHW asked to interview the person who regularly prepares household meals on the assumption that they are most knowledgeable about nutritional habits. This was most commonly the mother of the youngest generation living in the household, but very occasionally the grandmother or eldest sister. Interviewers obtained verbal consent prior to starting the questionnaire, and CHW translated from Spanish to Kichwa when necessary. We administered the questionnaire during the dry season (July and August) using the same technique in all communities. The questionnaire was administered in Chilcapamba in 2013 and in the three other communities in 2014. Two questions were added to the questionnaire in 2014: household crowding and household income.

The questionnaire contained four sections: demographic information, agricultural information, food frequency and food security. The demographic section contained 14 questions relating to participant age, marital status, level of income, level of education and household characteristics. Income was converted from a continuous variable into a binomial using categories below and above minimum wage (US\$340/month). The agriculture section contained nine questions regarding the type of crops grown and animals raised, whether they were used for sale or consumption, the use of fertiliser or pesticides, and the use of traditional agricultural practices. The food frequency section asked participants to identify whether 21 types of foods had been consumed in their household in the last 24 hours. We developed the list of foods from dietary habits of the population with input from a nutritionist familiar with Latin American diets, and aimed to recognise both traditional and Western food items. We did not establish the amount of foods consumed. We did not inquire about hunting practices as this is not part of the practices of these communities.

The Latin American Household Food Security Measurement Scale (ELCSA) is validated for use in Latin America to determine the level of food security based on the United States Department of Agriculture household food insecurity access scale. ${ }^{23}$ It consists of 15 questions regarding frequency of events in the last month: feeling worried about having enough food, eating less than needed so children could have enough and not having enough food, among others. The ELCSA places households into categories of absent, light, moderate and severe food insecurity, but we used a binomial of food secure (including the absent and light categories) and food insecure (including moderate and severe categories).

We wrote all sections of the questionnaire first in English and later translated them to Spanish, with review by $\mathrm{CHW}$ to ensure agreement with local language use.
We completed hard copies of questionnaires at the time of each household interview and later entered data into Excel spreadsheets.

\section{Biometric assessments of children}

The authors (SM in Chilcapamba and ES and JW in all other communities), with assistance of trained CHW, measured and weighed children between the ages of 6 months and 12 years living in the surveyed households at three centralised measurement locations (schoolhouses within each community). Parents gave their verbal consent at the time of questionnaire administration, and they brought their children to the predetermined site for measurement. Children were measured within 2 weeks of their household having completed the questionnaire. We measured the height (in centimetres) and weight (in kilograms) of each child and recorded values using standardised techniques, ${ }^{24}$ height against a wall with a measuring tape secured in place and a platform placed over the head of the child (MIES Wooden Measuring Rod 2011). We measured weight with a calibrated portable scale (Measuretek Portable Digital Scale SN0079099).

We plotted each child's height and age (HFA), as well as their body mass index (BMI, index of weight for height) and age to assess if they were stunted or overweight, respectively. We used WHO growth curves. Stunting was defined as HFA two or more SD below average, and overweight was defined as BMI two or more SD above average. $^{25}$

\section{Quantitative analysis}

We performed a quantitative analysis using CIETmap (V.2.5 beta 9.5), ${ }^{26}$ an epidemiological analysis program that uses the open-source $\mathrm{R}$ programming language. We calculated the proportion for each variable and the corresponding percentage. The units of analysis were children. The analysis related three main outcomes (ie, stunting, overweight and food security) with the items on the questionnaires. Analysis excluded missing data.

Bivariate analysis tested unadjusted associations between outcomes and household or community factors and determined the OR and Cornfield 95\% CI. ${ }^{27}$ We adjusted for clustering (by community) using the method of Lamothe (ORa and 95\% CIa) to avoid overestimation of statistical confidence. ${ }^{28}$ The basic principle is that a cluster sample has a smaller variance than a random sample of the same size, due to the common sense principle that people living together tend to be more similar than those living apart. In statistical terms, this would be expressed in more narrow CIs.

We used the Mantel-Haenszel procedure to determine the independence of significant associations found during bivariate analysis. ${ }^{29}$ This multivariate analysis saturated model included all significant associations from the bivariate analysis for each outcome; we excluded variables stepwise excluding the weakest associations first until only the associations significant at the $5 \%$ level remained. 


\section{Patient and public involvement}

The research topic of childhood nutrition and growth was determined by the CHW, after discussion with participant community members and leaders. The researchers then developed the specific research questions and outcome measures with knowledge of the communities from previous work through the TEACH project. The CHW were involved in the study design by reviewing questionnaires to ensure appropriateness, and they were critical in recruitment and data collection. Following preliminary analysis, the researchers prepared a fact sheet that the CHW disseminated and discussed with each community.

\section{RESULTS}

\section{Qualitative findings}

We held five discussion groups with 6-10 participants in each: three groups composed of mothers (in Arrayanes, Iltaqui and Morales Chupa), and two groups of farmers (in Morales Chupa and Iltaqui).

We found convergence in the discussions with mothers and farmers about nutrition and agriculture, respectively. For example, farmers said agricultural practices had changed because they grow fewer traditional grains; mothers said eating less of their traditional grains could be a cause of childhood malnutrition. All three communities identified irrigation, loss of agricultural traditions and eating less quinoa as important factors. Other factors mentioned include: using cooking oil, consuming rice, use of chemicals in agriculture, level of income, parasite infections and land area available for farming (table 1).

\section{Quantitative information}

A total of 139 households across four communities answered the questionnaire and consented to the measurement of their children. Three households (two in Arrayanes and one in Morales Chupa) did not participate because interviewers were unable to contact them or they refused. The respondent most commonly had an elementary school level education and cared for a household of seven family members on average. Most households earn income less than or equal to the minimum wage of the region (US $\$ 340 /$ month). Table 2 summarises the frequencies of the factors under study.

We obtained anthropometric measurements on 298 children. A small, unknown number of children living in households that completed the questionnaire were not present to be measured. Based on HFA, we found that approximately half of the children in each community are stunted (144/296 or $48.6 \%)$, less than half of the children in each community are overweight (129/298 or $43.3 \%$ ) and a small proportion of children are both stunted and overweight (46/298 or $15.4 \%)$. We found no relationship between stunting and overweight (ORa 1.41, $95 \%$ CIa 0.87 to 2.32 ). The majority of children in all four communities live in a food insecure household and this ranged from $85.2 \%$ (75/88 in Chilcapamba) to $48.8 \%$ (21/43 in Arrayanes).
Most children live in households that consume a daily diet comprised of rice (204/298 or $68.5 \%)$, corn $(239 / 298$ or $80.2 \%)$, potatoes $(249 / 298$ or $83.6 \%)$, fruits $(214 / 298$ or $71.8 \%)$ and vegetables $(268 / 298$ or $89.9 \%)$. Just under half of the respondents (143/288 or 49.6\%) report eating meat in the past 24 hours. We found less frequent consumption of quinoa $(41 / 298$ or $13.8 \%)$, fish $(31 / 298$ or $10.4 \%)$, eggs $(98 / 298$ or $32.9 \%)$ and milk $(119 / 298$ or $39.9 \%)$.

Most children live in a household that owned animals $(251 / 298$ or $84.2 \%)$, and approximately half live in a household that sold their livestock for profit (142/273 or $52 \%)$. A minority of children live in households that sold their crops for profit (68/289 or 23.5\%). Approximately half of children live in households that followed traditional agricultural practices (93/210 or $44.3 \%)$ and the majority live in households that did not report using chemicals in their agricultural practices $(185 / 193$ or $95.9 \%)$.

Bivariate analysis identified significant associations of risk factors and the three tested outcomes (table 3). Further analysis identified significant associations that remained independent after multivariate analysis (table 4). A child living in a household that sold livestock, have an illiterate primary caretaker or does not have access to irrigation is more likely to be stunted. Male children and those who live in a household that sells livestock are more likely to be overweight. Children who live in a household that earns less than minimum wage are more likely to be food insecure, while children who live in a household that consumed quinoa in the past 24 hours are more likely to be food secure (table 4).

\section{DISCUSSION}

There was an association between socioeconomic factors and children's growth status and household food insecurity among indigenous Andean Kichwa in Ecuador. Caretaker illiteracy and household income below minimum wage correlate with childhood stunting and food insecurity, respectively. Additionally, the sale of livestock was significantly associated with childhood stunting and overweight. Lastly, access to irrigation was found to correlate with childhood stunting.

Stunting and overweight affected almost half of children. The prevalence of stunting in the four communities investigated is similar to other indigenous groups in Ecuador. ${ }^{20}$ Similar to the body size changes noted in Amazonian Ecuador, ${ }^{17}$ the increasing prevalence of overweight children in Indigenous Andean Ecuador suggests that these communities are also in a transition process.

Access to irrigation was associated with less stunting in children. Research done in Latin America ${ }^{31} 32$ and rural Pakistan shows that irrigation can be protective against food insecurity. ${ }^{33}$ Given the mountainous terrain and the presence of a dry and rainy season, irrigation is especially important to the communities involved in this study. It ensures a consistent source of water for their crops and 
Table 1 Risk factors for poor childhood nutrition identified by mothers and farmers

\section{Factors identified by discussion groups \\ Concerns expressed by community members}

Importance rating * Relevant quotations

\section{Both mothers and farmers}

Loss of traditional Loss of ancestral grains due to agriculture techniques insects and crop failure

- The use of chemicals (fertiliser/ pesticides)

- Loss of the manure from traditional animals

- Not respecting the phases of the moon when cultivating

\begin{tabular}{|c|c|c|c|}
\hline $\begin{array}{l}\text { Eating fewer } \\
\text { traditional foods }\end{array}$ & $\begin{array}{l}\text { Increased use of cooking oil and rice } \\
\text { Decreased consumption of quinoa: } \\
\text { takes longer to prepare } \\
\text { Availability of unhealthy snacks at } \\
\text { school }\end{array}$ & $\begin{array}{l}\text { Morales Chupa } \\
\text { Mothers: } 5 \\
\text { Arrayanes } \\
\text { Mothers: } 3 \\
\text { Iltaqui } \\
\text { Mothers: } 2 \\
\text { Farmers: } 3\end{array}$ & $\begin{array}{l}\text { Today our children eat rice, spaghetti, } \\
\text { and chicken. } \\
\text { We are very lazy because the grains } \\
\text { take a long time to cook and we don't } \\
\text { have time. }\end{array}$ \\
\hline Level of income & $\begin{array}{l}\text { Not enough money to buy foods that } \\
\text { they are unable to grow themselves }\end{array}$ & $\begin{array}{l}\text { Morales Chupa } \\
\text { Farmers: no score } \\
\text { Arrayanes } \\
\text { Mothers: } 1 \\
\text { Iltaqui } \\
\text { Mothers: } 5 \\
\text { Farmers: no score }\end{array}$ & $\begin{array}{l}\text { We don't have a lot of grains because } \\
\text { the crop harvests are decreased, and } \\
\text { we cannot buy them. }\end{array}$ \\
\hline \multicolumn{4}{|c|}{ Mothers only (regarding nutrition) } \\
\hline \multicolumn{4}{|c|}{ Farmers only (regarding agriculture) } \\
\hline $\begin{array}{l}\text { Access to } \\
\text { irrigation }\end{array}$ & $\begin{array}{l}\text { Changing climate and rain patterns } \\
\text { force farmers to depend on irrigation } \\
\text { New crops require more water to } \\
\text { grow }\end{array}$ & $\begin{array}{l}\text { Morales Chupa } \\
\text { Farmers: } 4\end{array}$ & $\begin{array}{l}\text { We cannot grow food when it doesn't } \\
\text { rain; if the climate was as it was } \\
\text { before this would not be a problem. } \\
\text { The absence of irrigation has created } \\
\text { a challenge for the cultivation of some } \\
\text { crops, especially in this dry season. }\end{array}$ \\
\hline Land area & $\begin{array}{l}\text { Inherited land is divided among all } \\
\text { children decreasing the area used to } \\
\text { sustain a family } \\
\text { Not enough room to expand } \\
\text { Decreasing soil fertility and land } \\
\text { overuse }\end{array}$ & $\begin{array}{l}\text { Illtaqui } \\
\text { Farmers: } 2\end{array}$ & $\begin{array}{l}\text { Land areas are divided each } \\
\text { generation among all the children, so } \\
\text { each one gets a smaller piece. }\end{array}$ \\
\hline
\end{tabular}

*From 1 least to 5 most important.

thus a reliable source of nutrition for families. Discussion group participants explained that this is especially true in recent years where rain patterns have become unpredictable. La Frenierre et al has documented rain pattern changes within the region, ${ }^{34}$ and other reports have noted the importance of irrigation in the absence of consistent rainfall. ${ }^{35}$

Other studies have used quantity of agricultural products sold as a proxy for market integration. ${ }^{36}$ In our study, selling animals was associated with both overweight and stunting which may indicate an incomplete transition from subsistence farming to market integration, where

Mothers: 4

Farmers: 5

Arrayanes

Mothers: 4

Iltaqui

Mothers: 4

Farmers: 5
Morales Chupa

Mothers: 5

Arrayanes

Mothers: 3

Farmers: 3

Arrayanes

Iltaqui

Mothers: 5

Farmers: no score households have a diversified income stream as they move from agriculture towards wage labour or cash cropping. ${ }^{32}$ It may also indicate that there is a wide range of reasons that households sell animals; for example, a poorer household might sell an animal in a desperate situation, whereas a household of higher socioeconomic status would be more likely to plan to sell an animal for profit.

Male children were more likely to be overweight than female children, a trend that was not documented in school children in an Ecuadorian city, ${ }^{37}$ and appears to be the opposite of the trend documented for adults in

Morales Chupa $\quad$ We are losing our love of the Earth 


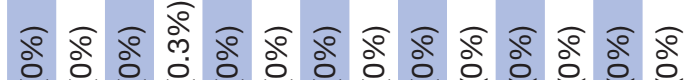

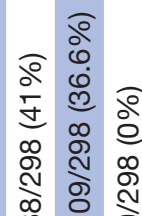

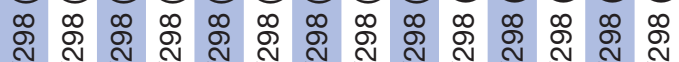

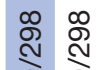

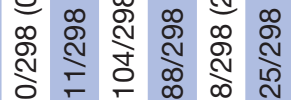

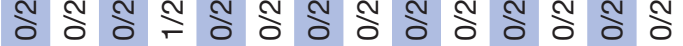

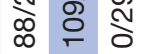

๖े वे ฏे

$\infty$

న్

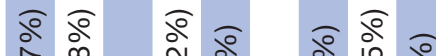

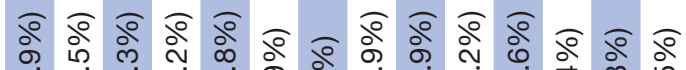

वे

ஓे बें

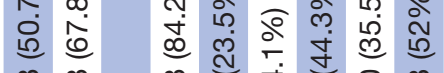

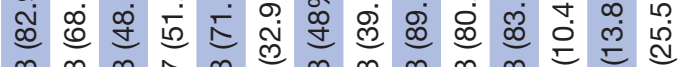

急

অ.

o

寽 空

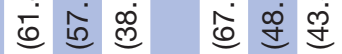

으

品

ळे

ণิ

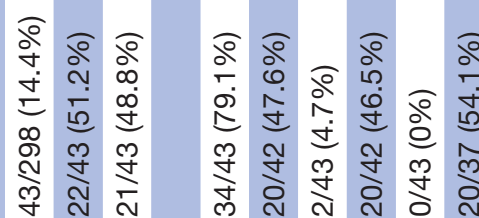

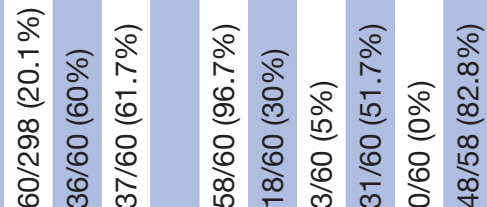

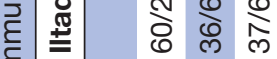

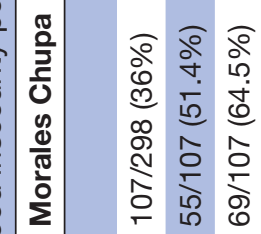

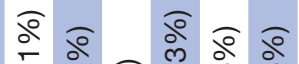
एं ए. 든

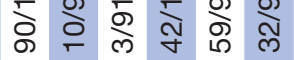

\section{\% 8}

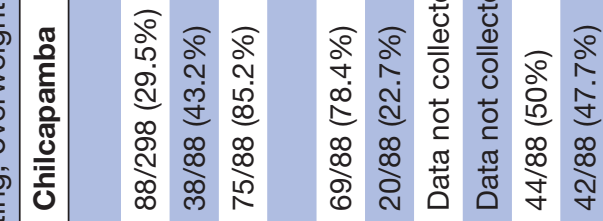

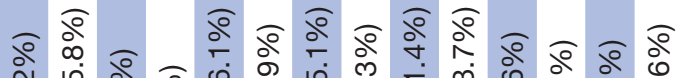

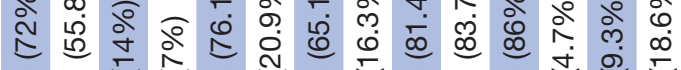

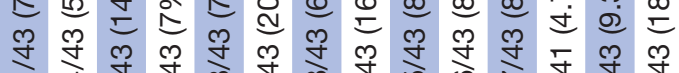

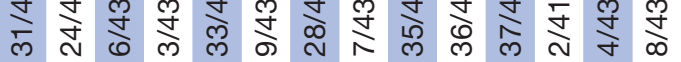

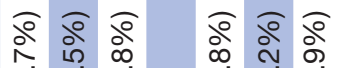

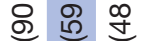

ม ₹

के ڤે

过 过

m

ते 유 एक

융

$\stackrel{\overrightarrow{\vec{F}}}{\stackrel{9}{+}}$

$\frac{\sqrt{0}}{\frac{0}{0}}$

ळ

$\vec{\circ}$

$\overrightarrow{\vec{\omega}}$

잉.

กิ

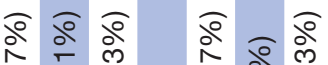

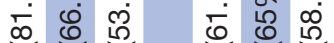
$\therefore$ ৫

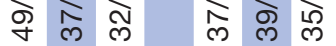

i ए

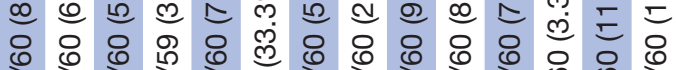

命

к वें

ळ

× $\infty$ in

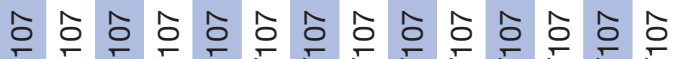

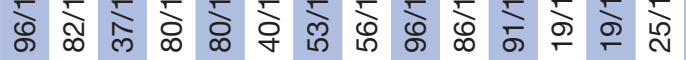

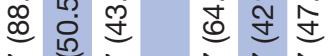

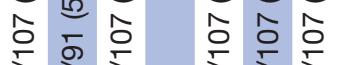

每

ว

仓े

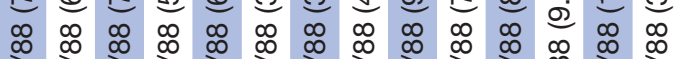

ఫ

$\stackrel{\overline{0}}{\underline{\underline{0}}}$

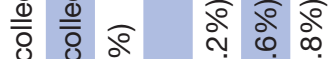

艹

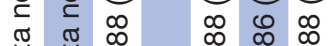

舟

苋 in $\frac{+}{5}$
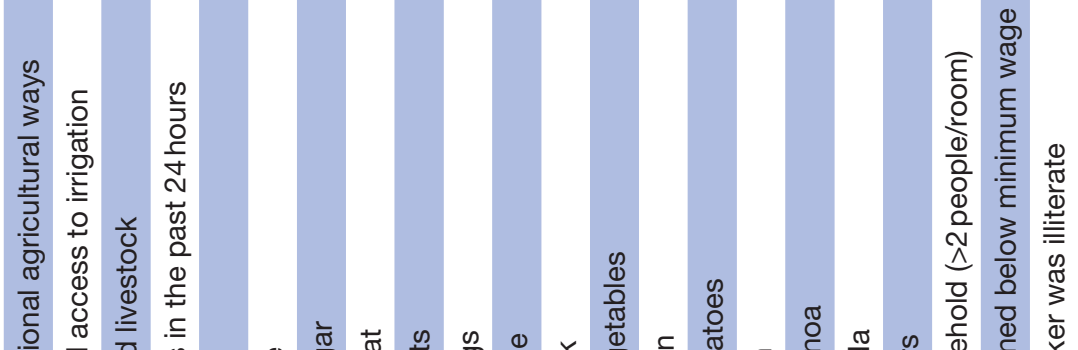

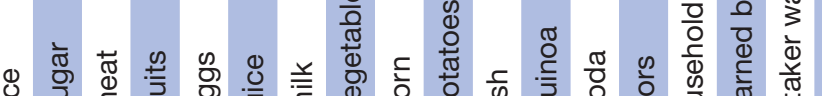

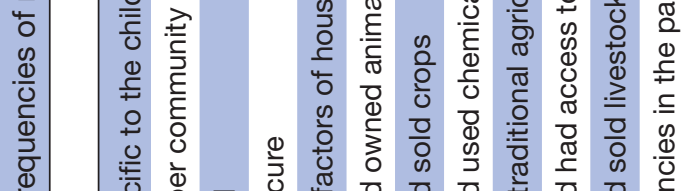

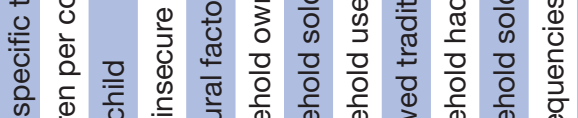

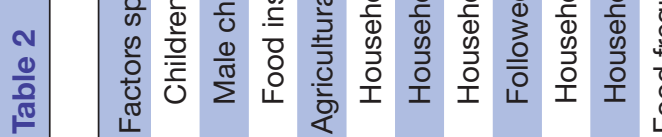

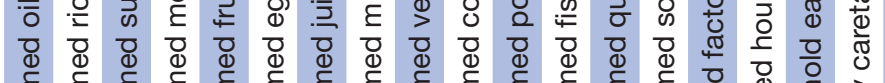




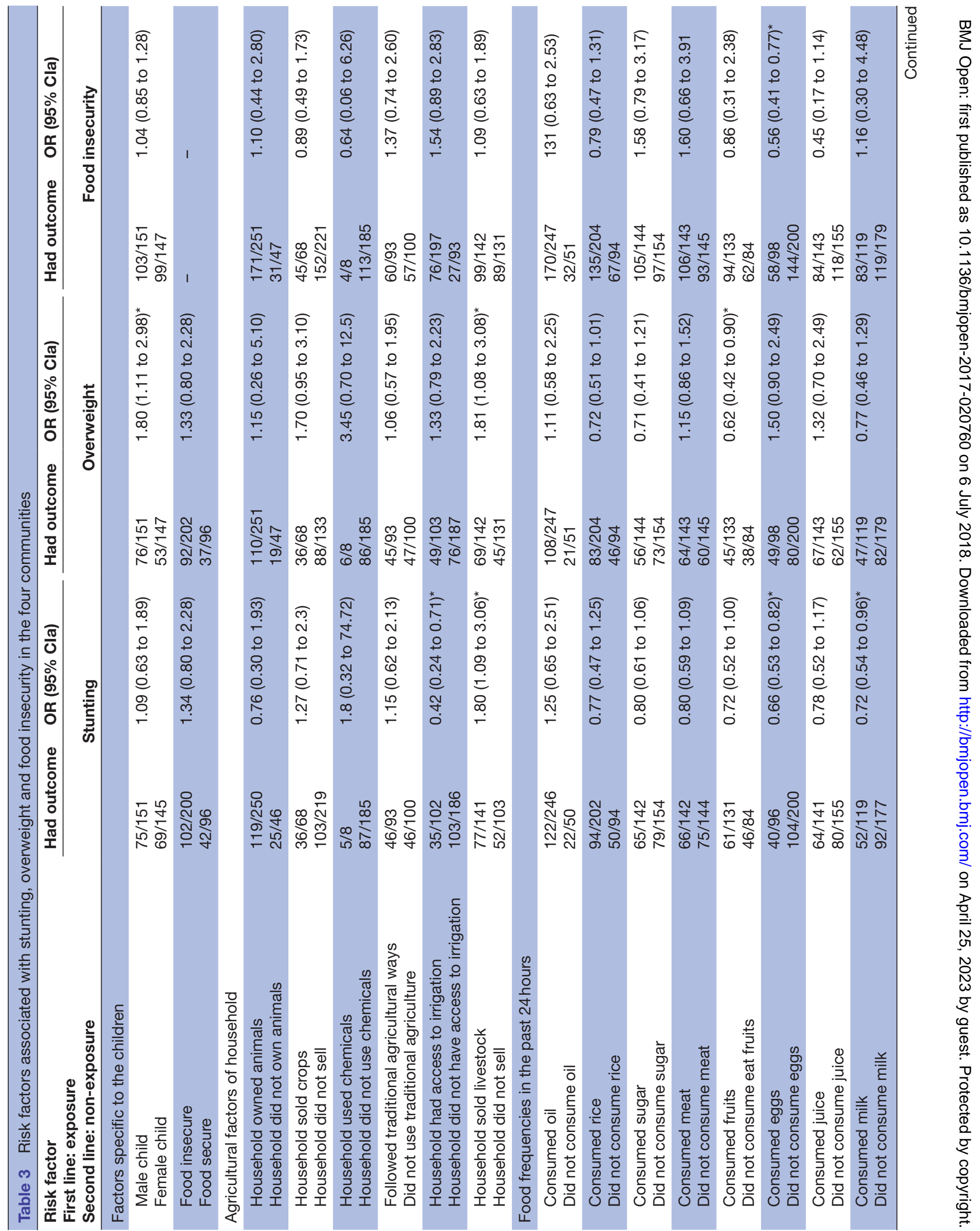




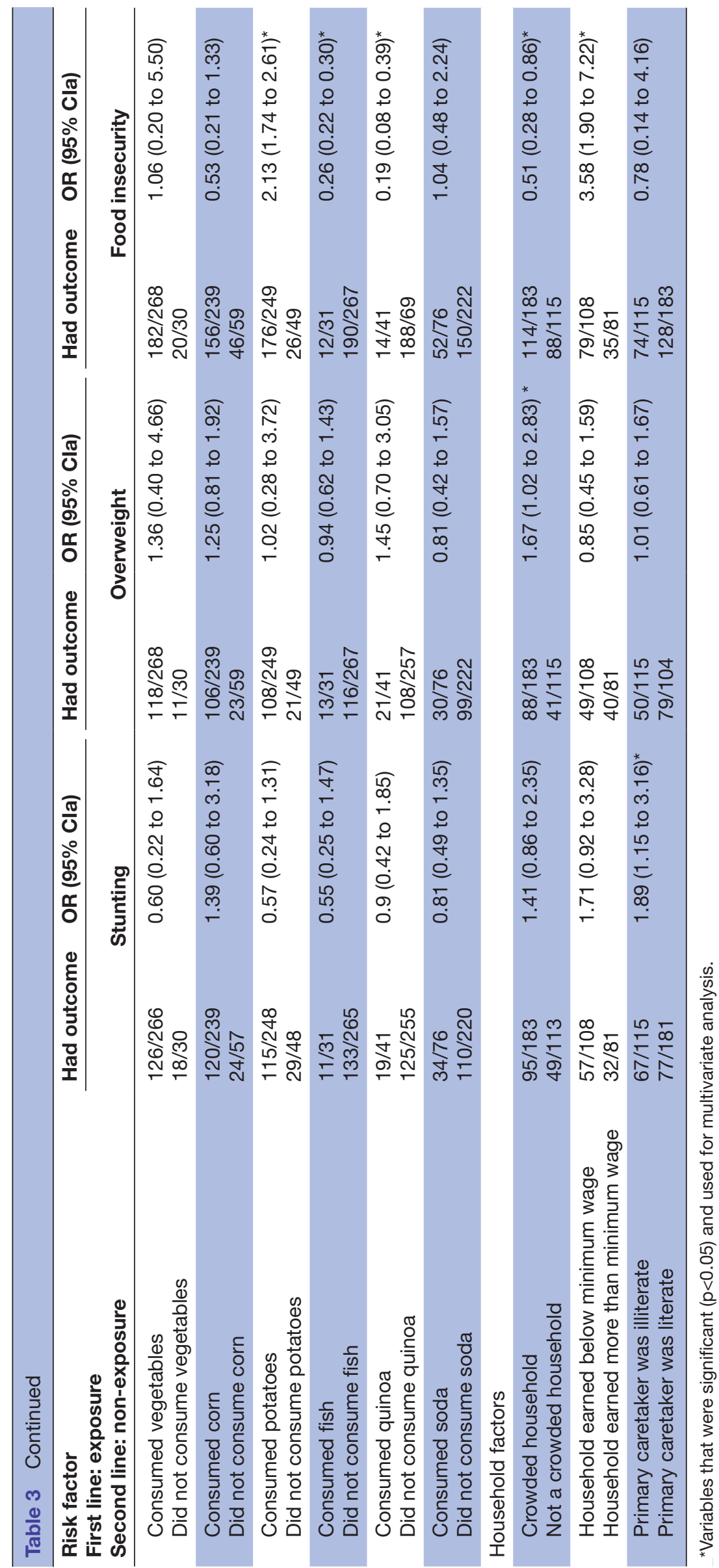


Table 4 Final results of multivariate analysis of risk factors associated with stunting, overweight and food insecurity in the four communities

\begin{tabular}{|c|c|c|c|}
\hline Exposure & Adjusted OR & $95 \%$ Cla & Cluster adj $\mathrm{X}^{2} \mathrm{MH}$ \\
\hline Household sold livestock & 1.77 & 1.06 to 2.95 & 4.74 \\
\hline Household had access to irrigation & 0.47 & 0.27 to 0.81 & 7.46 \\
\hline \multicolumn{4}{|l|}{ Overweight } \\
\hline Household sold livestock & 2.14 & 1.14 to 4.02 & 5.59 \\
\hline \multicolumn{4}{|l|}{ Food insecurity } \\
\hline Household earned below minimum wage & 2.90 & 1.56 to 5.41 & 11.25 \\
\hline Consumed quinoa & 0.17 & 0.06 to 0.48 & 11.16 \\
\hline
\end{tabular}

Cla, Cls using the method of Cornfield, adjusted for clustering with the method of Lamothe; cluster adj $\chi^{2} \mathrm{MH}$, clusteradjusted $\chi^{2}$ Mantel-Haenszel.

Ecuador. ${ }^{38}$ Preferential feeding of male children has been documented in other regions of the world but has not been clearly seen in the Andes. ${ }^{39}$ This difference in nutritional status between males and females may be attributable to variations in activity levels and food consumption patterns among individuals within a household, ${ }^{40}$ which may differ depending on the degree of market integration of a household.

In our study, caretaker literacy was inversely associated with stunting. Urke et al suggested that women who are better educated are more likely to take advantage of the few available resources in their rural setting and therefore more able to secure good nutrition for their children. ${ }^{41}$ Furthermore, the quantitative analysis revealed that an income below minimum wage was significantly associated with food insecurity. Discussion groups also indicated that income was an important factor in food insecurity and nutrition. Low income is associated with food insecurity and poor health status in both developed and developing countries $^{42}{ }^{43}$; the difference lies in overweight, where in developed countries it is associated with poverty, ${ }^{42}$ but in low-middle income countries it is associated with higher socioeconomic status. ${ }^{44}$ However, programmes that address income independent of other variables (like education) are ineffective at improving childhood health status. ${ }^{45} 46$ Larrea and Kawachi suggested that socioeconomic inequality is a predictor of poorer health outcomes independent of absolute income. ${ }^{47}$ Conversely, poverty alleviation in addition to maternal education may work symbiotically to improve childhood health. ${ }^{48}$ Evidence like this reveals the high potential for confounding between income, maternal education and childhood health. ${ }^{49}$

This study further demonstrated that households that reported consumption of quinoa were less likely to report food insecurity. Quinoa is an important part of traditional agriculture in Ecuadorian highlands and was used in this study as a proxy. All three communities voiced that the loss of traditional agricultural practices and decreased consumption of traditional food were main contributors to childhood malnutrition. Many mothers described difficulty enticing their children to eat traditional foods, because they preferred the processed snacks available at school. In Brazil, young people had less interest in consuming wild edible plants due to perceived negative cultural acceptance. ${ }^{50}$ Other researchers have argued for the value of maintaining local food biodiversity as well as traditional agricultural knowledge. ${ }^{35} 51$ One study found that higher income reaped from high-intensity, highinput farming of non-traditional crops was associated with worse nutritional outcomes for children in those households compared with moderate-intensity to low-intensity farming households that rely on locally available inputs. ${ }^{52}$ Several factors, including perceived usefulness or convenience of alternatives, may drive the loss of traditional knowledge in cultural transition, ${ }^{53}$ and this loss may have costs associated with poorer childhood health outcomes like growth potential, stunting and excessive immunostimulation. ${ }^{54}$

This study faced several limitations. Analysis was limited by low statistical power despite the inclusion of almost all households in the participating communities. This is a common feature of studies involving remote indigenous communities. Food frequency questionnaires provide only a limited snapshot into food habits and can miss important differences in seasonal and daily nutritional intake. Food frequency questionnaires do not account for the quantity of a food group consumed and can therefore overestimate or underestimate the intake of certain foods. Although we tried to maintain the same methods between the two periods of data collection, two items were added to the questionnaire for the second summer of data collection (ie, household crowding and household income). We encountered some difficulty communicating with participants who spoke only Kichwa; we were able to rely on CHW for translation assistance, but some information may have been omitted. 


\section{CONCLUSIONS}

The indigenous communities we partnered with are in a tumultuous period of cultural, nutritional and epidemiological transitions, and many complex, internal and external factors affect these processes, including market integration, weather patterns and community mindset. Our study suggests that some deleterious health effects on children could be minimised with effective community interventions. This study is significant because it provides the community with information to guide future health interventions, and data to support the path towards those interventions (eg, funding, regional governmental support, community engagement). Deliberation among community leaders and members over the information this study provides will be critical to determine how best to address these problems of childhood stunting, overweight and food insecurity. Important factors for discussion include ways to maintain and grow traditional knowledge and resources, and ways to adopt and improve on Western resources like irrigation, primary health education, gender equality and income.

Acknowledgements Many thanks to Luz Maria Conejo for her support and coordination in the field, Andrea Evans for her vision of the TEACH project, and all of the CHW.

Contributors ES and JW contributed equally to the project and were involved in project design, securing funding in 2014 and ethical approval in 2014. They were also responsible for data collection in the communities of Iltaqui, Morales Chupa and Arrayanes in 2014. Both authors administered the questionnaire along with the $\mathrm{CHW}$ and facilitated the discussion groups with the support of JM. They also drafted the original manuscript with the support of IS (Methods and Results sections) and JPP (Background and Discussion sections). IS led the statistical analysis with CIETmap and the Mantel Haenszel procedure. IS and JPP reviewed the qualitative data and edited the results section. JW, ES and IS addressed reviewers' comments. SM developed the original questionnaire in 2013 and applied for funding and ethical approval in 2013; she administered the questionnaire along with the $\mathrm{CHW}$ in Chilcapamba in 2013. JM was the leader of the CHW at the time of the project; she organised and assisted in data collection (2013 and 2014); she reviewed the questionnaires to ensure acceptance by communities and compatibility with local language and facilitated the discussion groups; she contributed particularly to the review of the Methods section of this manuscript and presented the results in Spanish and Kichwa to the involved communities. AD, in discussion with the CHW, initiated the study and was involved in project design and development. NA guided the data analysis and edited the manuscript.

Funding The study was funded by CIHR Health Professional Student Research Award, Clarke K McLeod Memorial Scholarship, Ivan Racheff Scholarship and Sir Edward W Beatty Memorial Scholarships. ES was funded by the CIHR Health Professional Student Research Award and the Clarke K McLeod Memorial Scholarship. JW was funded by the Ivan Racheff Scholarship. SM was funded by the Clarke K McLeod Memorial and Sir Edward W Beatty Memorial Scholarships. Funding was used for travel costs for the primary investigators. The authors thank the Global Health Program at McGill's Department of Family Medicine for its contribution to the financing of this publication.

Disclaimer The sponsors of the study had no role in study design, data collection, data analysis, data interpretation or writing of the report.

Competing interests None declared.

Patient consent Obtained.

Ethics approval The Internal Review Board of McGill University approved this study and its use of human subjects (IRB Study Number A04-B11-12B). We attest that we have obtained appropriate permissions and paid any required fees for use of copyright protected materials.

Provenance and peer review Not commissioned; externally peer reviewed.
Data sharing statement The datasets generated during or analysed during the current study will be available upon request from the corresponding author. Before the information can be shared, the requester will need to present a plan for data analysis. Also, the requester will need to complete the procedure for ethical approval of the secondary analysis following the procedures defined by McGill University's Institutional Review Board and the agreements with communities to ensure the protection of the participants.

Open access This is an open access article distributed in accordance with the Creative Commons Attribution Non Commercial (CC BY-NC 4.0) license, which permits others to distribute, remix, adapt, build upon this work non-commercially, and license their derivative works on different terms, provided the original work is properly cited and the use is non-commercial. See: http://creativecommons.org/ licenses/by-nc/4.0/

(C) Article author(s) (or their employer(s) unless otherwise stated in the text of the article) 2018. All rights reserved. No commercial use is permitted unless otherwise expressly granted.

\section{REFERENCES}

1. Instituto Nacional de Estadística y Censos- Resultados. http://www. ecuadorencifras.gob.ec/resultados/ (accessed 31 Mar 2017).

2. Freire WB, Silva-Jaramillo KM, Ramírez-Luzuriaga MJ, et al. The double burden of undernutrition and excess body weight in Ecuador. Am J Clin Nutr 2014;100:1636S-43.

3. Freire W, Belmont P, Gómez L, et al. Tomo I: Encuesta Nacional de Salud y Nutrición de la población ecuatoriana de cero a 59 años. ENSANUT-ECU 2012. Quito-Ecuador. Quito: Ministerio de Salud Pública/Instituto Nacional de Estadísticas y Censos, 2014. http:// www.ecuadorencifras.gob.ec/documentos/web-inec/Estadisticas Sociales/ENSANUT/MSP_ENSANUT-ECU_06-10-2014.pdf. (accessed 31 Mar 2017).

4. Davila F. Ecuador: la desnutrición en la población indígena y afroecuatoriana menor de cinco años. $2008 \mathrm{http} / / / w w w$. ecuadorencifras.gob.ec/documentos/web-inec/Bibliotecas/Estudios/ Estudios_Socio-demograficos/La_Desnutricion_en_la_Poblacion_ Indigena_y_Afroecuat.pdf (accessed 27 Mar 2018).

5. Ortiz J, Van Camp J, Wijaya S, et al. Determinants of child malnutrition in rural and urban Ecuadorian highlands. Public Health Nutr 2014;17:2122-30.

6. Urlacher SS, Blackwell AD, Liebert MA, et al. Physical growth of the shuar: Height, Weight, and BMI references for an indigenous amazonian population. Am J Hum Biol 2016;28:16-30.

7. Larrea C, Freire W. Social inequality and child malnutrition in four Andean countries. Rev Panam Salud Publica 2002;11:356-64.

8. Pawson IG, Huicho L, Muro M, et al. Growth of children in two economically diverse Peruvian high-altitude communities. Am J Hum Biol 2001;13:323-40.

9. Urke HB, Bull T, Mittelmark MB. Child diet and healthy growth in the context of rural poverty in the peruvian andes: what influences primary caregivers' opportunities and choices? Glob Health Promot 2013;20:5-13.

10. Victora CG, Adair L, Fall C, et al. Maternal and child undernutrition: consequences for adult health and human capital. Lancet 2008;371:340-57.

11. Sawaya AL, Roberts S. Stunting and future risk of obesity: principal physiological mechanisms. Cad Saude Publica 2003;19(Suppl 1):S21-S28.

12. Liebert MA, Snodgrass JJ, Madimenos FC, et al. Implications of market integration for cardiovascular and metabolic health among an indigenous Amazonian Ecuadorian population. Ann Hum Biol 2013;40:228-42.

13. Godoy R, Reyes-García V, Byron E, et al. The effect of market economies on the well-being of indigenous peoples and on their use of renewable natural resources. Annu Rev Anthropol 2005;34:121-38.

14. Houck K, Sorensen MV, Lu F, et al. The effects of market integration on childhood growth and nutritional status: the dual burden of underand over-nutrition in the Northern Ecuadorian Amazon. Am J Hum Biol 2013;25:524-33.

15. Popkin BM. The nutrition transition and its health implications in lower-income countries. Public Health Nutr 1998;1:5-21.

16. Omran AR. The epidemiologic transition: a theory of the epidemiology of population change. 1971. Milbank Q 2005;83:731-57.

17. Urlacher SS, Liebert MA, Josh Snodgrass J, et al. Heterogeneous effects of market integration on sub-adult body size and nutritional 
status among the Shuar of Amazonian Ecuador. Ann Hum Biol 2016;43:316-29.

18. Waters WF. Globalization and local response to epidemiological overlap in 21st century Ecuador. Global Health 2006;2:8-13.

19. Thorpe KE, Allen L, Joski P. The role of chronic disease, obesity, and improved treatment and detection in accounting for the rise in healthcare spending between 1987 and 2011. Appl Health Econ Health Policy 2015;13:381-7.

20. Puertas B, Schlesser M. Assessing community health among indigenous populations in Ecuador with a participatory approach: implications for health reform. $J$ Community Health 2001;26:133-47.

21. Climate cotacachi: temperature, climate graph, climate table for cotacachi. https://en.climate-data.org/location/25394/ (accessed 18 May 2017).

22. Andersson N. Building the community voice into planning: 25 years of methods development in social audit. BMC Health Serv Res 2011;11(Suppl 2):S1.

23. Comité científico de la ELCSA. Escala Latinoamericana y Caribeña de Seguridad Alimentaria (ELCSA): Manual de uso y aplicaciones. 2012 http://www.fao.org/3/a-i3065s.pdf (accessed 8 Feb 2018).

24. Centres for Disease Control and Prevention. Anthropometry procedures manual. Hyattsville. $2007 \mathrm{http} / / /$ www.cdc.gov/nchs/data/ nhanes/nhanes 07 08/manual an.pdf (accessed 8 Feb 2018).

25. de Onis M, Onyango AW, Borghi E, et al. Development of a WHO growth reference for school-aged children and adolescents. Bull World Health Organ 2007;85:660-7.

26. Wikipedia. CIETmap. https://en.wikipedia.org/wiki/CIETmap (accessed 10 Mar 2017)

27. Monasta L, Andersson N, Ledogar RJ, et al. Minority Health and small numbers epidemiology: a case study of living conditions and the health of children in 5 foreign romá camps in Italy. 2008;98:2035-41.

28. Andersson N, Lamothe G. Clustering and meso-level variables in cross-sectional surveys: an example of food aid during the Bosnian crisis. BMC Health Serv Res 2011;11(Suppl 2):S15.

29. Mantel N. Chi-square tests with one degree of freedom; extensions of the mantel- haenszel procedure. J Am Stat Assoc 1963;58:690-700.

30. Blackwell AD, Pryor G, Pozo J, et al. Growth and market integration in Amazonia: a comparison of growth indicators between Shuar, Shiwiar, and nonindigenous school children. Am J Hum Biol 2009;21:161-71.

31. Perreault T. Social capital, development, and indigenous politics in ecuadorian amazonia*. Geogr Rev 2003;93:328-49.

32. Leah J, Pradel W, Cole DC, et al. Determinants of household food access among small farmers in the Andes: examining the path. Public Health Nutr 2012;16:1-10.

33. van der Hoek W, Feenstra SG, Konradsen F. Availability of irrigation water for domestic use in Pakistan: its impact on prevalence of diarrhoea and nutritional status of children. $J$ Health Popul Nutr 2002;20:77-84.

34. La Frenierre J, Mark BG. Detecting patterns of climate change at volcán chimborazo, ecuador, by integrating instrumental data, public observations, and glacier change analysis. Ann Am Assoc Geogr 2017; 107:979-97.

35. Cole DC, Huancayo H, Pacheco R, et al. Andean indigenous-mestizo peoples, agro- ecosystems \& human health: horticulture in Peru's montaro valley. Global indigenous health research symposium report, 2007:27-32.
36. Maltsoglou I, Tanyeri-Abur A. Transaction costs, institutions and smallholder market integration: potato producers in Peru. 2005 http://www.fao.org/tempref/docrep/fao/008/ae876e/ae876e00.pdf (accessed 8 Feb 2018).

37. Abril V, Manuel-y-keenoy B, Solà R, et al. Prevalence of overweight and obesity among 6-to 9-year-old school children in Cuenca, Ecuador: relationship with physical activity, poverty, and eating habits. Food Nutr Bull 2013;34:388-401.

38. World Health Organization. Diabetes. 2016 http://www.who.int/ diabetes/country-profiles/ecu en.pdf (accessed 30 Jan 2018)

39. Gittelsohn J, Vastine AE. Sociocultural and household factors impacting on the selection, allocation and consumption of animal source foods: current knowledge and application. J Nutr 2003;133:4036S-41.

40. Graham MA. Food allocation in rural Peruvian households: concepts and behavior regarding children. Soc Sci Med 1997;44:1697-709.

41. Urke HB, Bull T, Mittelmark MB. Socioeconomic status and chronic child malnutrition: Wealth and maternal education matter more in the Peruvian Andes than nationally. Nutr Res 2011;31:741-7.

42. Chaudry A, Wimer C. Poverty is not just an indicator: the relationship between income, poverty, and child well-being. Acad Pediatr 2016;16:S23-S29

43. Shahraki SH, Amirkhizi F, Amirkhizi B, et al. Household food insecurity is associated with nutritional status among iranian children. Ecol Food Nutr 2016;55:473-90.

44. Dinsa GD, Goryakin Y, Fumagalli E, et al. Obesity and socioeconomic status in developing countries: a systematic review. Obes Rev 2012;13:1067-79.

45. Fernald LC, Gertler PJ, Neufeld LM. Role of cash in conditional cash transfer programmes for child health, growth, and development: an analysis of Mexico's Oportunidades. Lancet 2008;371:828-37.

46. Forde I, Chandola T, Garcia S, et al. The impact of cash transfers to poor women in Colombia on BMl and obesity: prospective cohort study. Int J Obes 2012;36:1209-14.

47. Larrea C, Kawachi I. Does economic inequality affect child malnutrition? The case of Ecuador. Soc Sci Med 2005;60:165-78.

48. Hatt LE, Waters HR. Determinants of child morbidity in Latin America: a pooled analysis of interactions between parental education and economic status. Soc Sci Med 2006;62:375-86.

49. Gracey M, King M. Indigenous health part 1: determinants and disease patterns. Lancet 2009;374:65-75.

50. Cruz MP, Medeiros PM, Sarmiento-Combariza I, et al. "I eat the manofê so it is not forgotten": local perceptions and consumption of native wild edible plants from seasonal dry forests in Brazil. $J$ Ethnobiol Ethnomed 2014;10:45.

51. Kuhnlein HV. How ethnobiology can contribute to food security. $J$ Ethnobiol 2014;34:12-27.

52. Orozco FA, Cole DC. Charron DF, Tackling Challenges to Farmers' Health and Agro-Ecosystem Sustainability in Highland Ecuador $B T$ - ecohealth research in practice: innovative applications of an ecosystem approach to health. New York, NY: Springer New York, 2012:47-58.

53. Reyes-García V, Guèze M, Luz AC, et al. Evidence of traditional knowledge loss among a contemporary indigenous society. Evol Hum Behav 2013;34:249-57.

54. McDade TW, Reyes-García V, Blackinton P, et al. Ethnobotanical knowledge is associated with indices of child health in the Bolivian Amazon. Proc Natl Acad Sci U S A 2007;104:6134-9. 